\title{
Temporal Relations of the Complex Spike Activity of Purkinje Cell Pairs in the Vestibulocerebellum of Rabbits
}

\author{
Douglas R. Wylie, ${ }^{a}$ Chris I. De Zeeuw, ${ }^{b}$ and John I. Simpson \\ Department of Physiology and Biophysics, New York University Medical Center, New York, New York 10016
}

Parasagittal zones in the vestibulocerebellum contain Purkinje cells whose complex spike (CS) activity is modulated in response to rotational optokinetic stimulation (OKS) about either the vertical axis (VA) or a horizontal axis (HA) that is approximately perpendicular to the ipsilateral anterior canal. In rabbits, there are two VA zones in both the ventral nodulus and flocculus, two HA zones in the flocculus, and one HA zone in the ventral nodulus. We investigated the temporal relationship of the CS activity of Purkinje cell pairs in the same or different zones of the vestibulocerebellum in ketamine-anesthetized pigmented rabbits. A synchronous temporal relationship was defined as the tendency of the CS of each Purkinje cell to fire within, at most, 2 msec of one another. Generally, neurons in the same zone showed a tendency to exhibit CS synchrony. Of 82 pairs consisting of two Purkinje cells in the same zone (e.g., two nodulus HA cells), 33 were synchronous. In contrast, none of 26 pairs consisting of two neurons in functionally different zones (e.g., a VA cell paired with an HA cell), showed CS synchrony. Pairs consisting of neurons in spatially separated VA zones in the ventral nodulus also showed a tendency to be synchronously related (6/16), as did pairs consisting of a nodulus VA cell and a flocculus VA cell (3/14). The CS synchrony was higher during OKS in the preferred direction than during spontaneous activity. This is the first demonstration that CS synchrony in the vestibulocerebellum can be manipulated with a natural sensory stimulus.

[Key words: synchrony, rhythmicity, optokinetic, inferior olive, flocculus, nodulus, correlograms, cerebellum]

The inferior olive $(\mathrm{IO})$ projects as climbing fibers $(\mathrm{CFs})$ to the cerebellar cortex where they synapse onto Purkinje cells and give rise to complex spikes (CSs) (Thach, 1967). Inferior olivary neurons and, consequently, CSs of Purkinje cells, have been observed to fire rhythmically at a characteristic frequency of about $10 \mathrm{~Hz}$ (Llinás and Yarom, 1981a,b, 1986; Llinás, 1986, 1991; Llinás and Sasaki, 1989; Sasaki et al., 1989). Gap junctions between neurons in the IO are the morphological correlates of

\footnotetext{
Received Aug. 15, 1994; revised Oct. 13, 1994; accepted Oct. 18, 1994.

This research was supported by grants from NWO (R 95-260), KNAW, and NIH (NS-13742). D.R.W was supported by a postdoctoral fellowship from NSERC (Canada). C.I.D.Z. was supported by a fellowship from KNAW (The Netherlands).

Correspondence should be addressed to J. I. Simpson at the above address. aPresent address: Department of Psychology, University of Alberta, Edmonton, Alberta, Canada, T6G 2E9.

'Present address: Department of Anatomy, Erasmus University, P.O. Box 1738, Rotterdam, The Netherlands.

Copyright (C) 1995 Society for Neuroscience $0270-6474 / 95 / 152875-13 \$ 05.00 / 0$
}

electrotonic coupling (Llinás et al., 1974; Sotelo et al., 1974), which is thought to be responsible for the phenomenon of CS synchrony. Synchrony is the tendency of CSs of Purkinje cells to fire within a very brief interval of one another, often within the same millisecond. This phenomenon was first reported by Bell and colleagues (Bell and Grimm, 1969; Bell and Kawasaki, 1972), who recorded from Purkinje cell pairs, and by Llinás and colleagues (Llinás and Sasaki, 1989; Sasaki et al., 1989; Sugihara et al., 1993), who recorded from arrays of up to 96 cells. The importance of electrotonic coupling was recently supported by the discovery of the dendritic lamellar body that is associated with dendrodendritic gap junctions (De Zeeuw et al., in press a). This organelle is present in all olivary subnuclei and its density is higher in the IO than in any other brain area.

Generally, the temporal relationship among CSs is strongest within a parasagittal plane (Bell and Kawasaki, 1972; Llinás and Sasaki, 1989; Sasaki et al., 1989; Sugihara et al., 1993), reflecting the sagittal zonal organization of the $\mathrm{CF}$ input to the cerebellum (Groenewegen et al., 1979). As shown in Figure 1, the ventral nodulus contains four sagittal zones and the flocculus contains five zones on each side of the brain. These zones can be identified on the basis of CS modulation in response to rotational optokinetic stimulation (OKS). Purkinje cells in zones VA1 and VA2 of the ventral nodulus and zones 2 and 4 of the flocculus receive their $\mathrm{CF}$ input from the caudal dorsal cap (cdc) of the IO and respond best to OKS about the vertical axis (Simpson et al., 1981; Balaban and Henry, 1988; Graf et al., 1988; Katayama and Nisimaru, 1988; Leonard et al., 1988; Kano et al., 1990a; Kusonoki et al., 1990; De Zeeuw et al., in press b; Tan et al., in press; Wylie et al., in press; see also Barmack and Shojaku, 1992). Zone HA of the ventral nodulus and zones 1 and 3 of the flocculus contain two Purkinje cell types whose CSs are modulated in response to OKS about a horizontal axis that is approximately perpendicular to the ipsilateral anterior semicircular canal (Fig. 1) (Simpson et al., 1981; Graf et al., 1988; Kano et al., 1990a,b; Kusonoki et al., 1990; De Zeeuw et al., in press b; Tan et al., in press; Wylie et al., in press). The two cell types differ with respect to the origin of their $\mathrm{CF}$ input and ocular dominance (see Fig. 4). Contra- $45^{\circ}$ (c45) cells receive their $\mathrm{CF}$ input from the rostral dorsal cap (rdc) and have a contralateral ocular dominance. Under monocular viewing conditions, $c 45$ cells are maximally excited in response to clockwise (cw) rotation about an axis oriented at about $45^{\circ}$ contralateral azimuth (Simpson et al., 1981; Graf et al., 1988; Leonard et al., 1988). Ipsi- $135^{\circ}$ (i135) cells receive their CF input largely from the ventrolateral outgrowth (vlo) and have an ipsilateral ocular dominance. Under monocular viewing conditions, i135 cells are maximally excited in response to counterclockwise $(\mathrm{ccw})$ rota- 


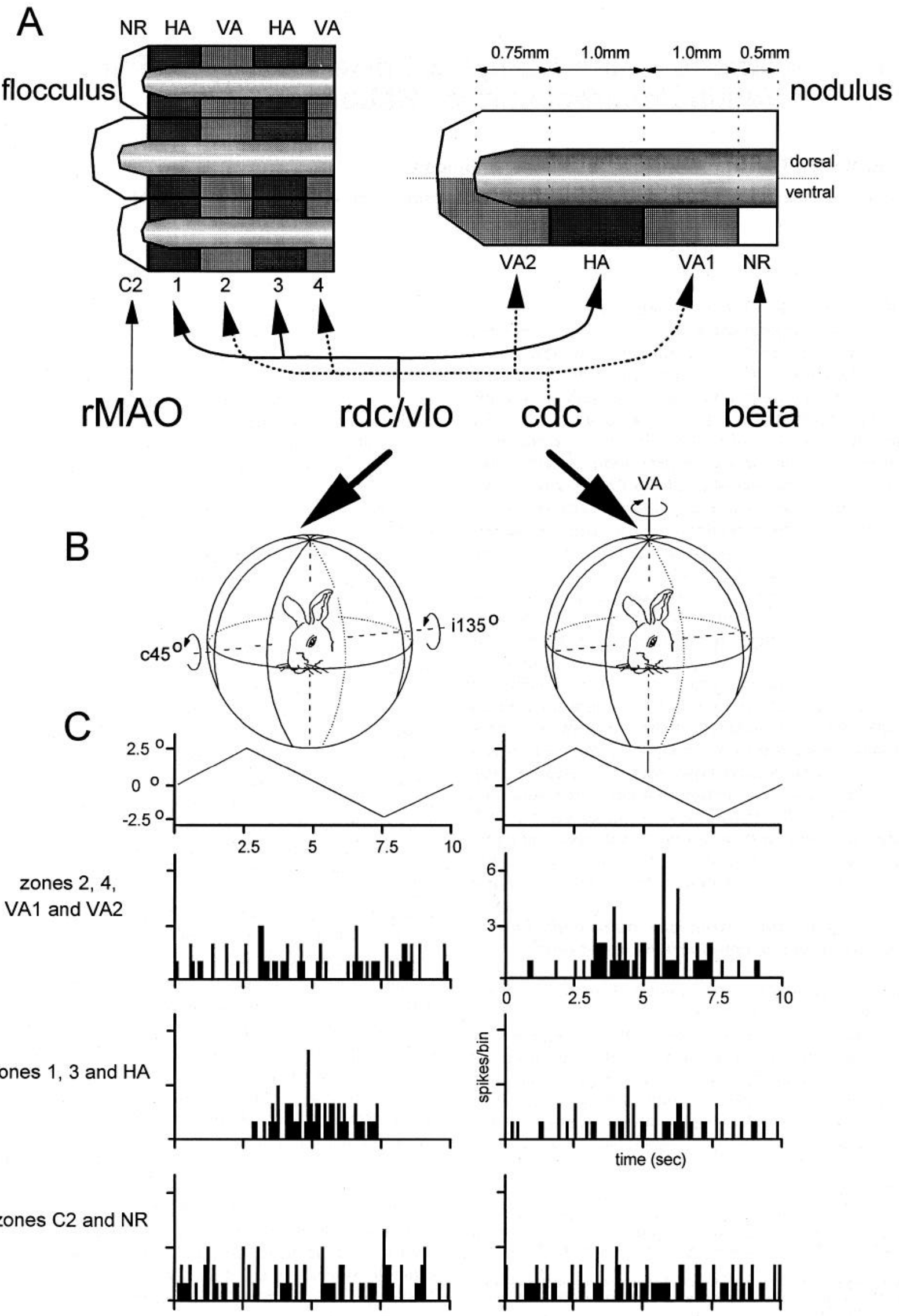

Figure 1. Zonal organization of the rabbit flocculus and ventral nodulus. The five zones of the flocculus, the four zones of the ventral nodulus, and the origin of their climbing fiber inputs are shown $(A) . C$ shows examples of the CS modulation of Purkinje cells in each of the zones of the left ventral nodulus and flocculus in response to optokinetic stimulation. The OKS was produced by a planetarium projector (Simpson et al., 1981; 
Table 1. Classification of the complex spike temporal relationship of Purkinje cell pairs

\begin{tabular}{|c|c|c|c|c|c|}
\hline & Total & $\begin{array}{l}\text { Synchronous } \\
(1-2 \mathrm{msec})\end{array}$ & $\begin{array}{l}\text { Perisynchronous } \\
(5-10 \mathrm{msec})\end{array}$ & $\begin{array}{l}\text { Contemporaneous } \\
(20-50 \text { insec) }\end{array}$ & Unrelated \\
\hline \multicolumn{6}{|c|}{ Pairs consisting of two Purkinje cells in the same zone } \\
\hline VA1-VA1 & 33 & $12(36 \%)$ & $4(12 \%)$ & $4(12 \%)$ & $13(39 \%)$ \\
\hline VA2-VA2 & 6 & $5(83 \%)$ & $1(17 \%)$ & 0 & 0 \\
\hline$c 45-c 45$ & 14 & $3(21 \%)$ & $4(29 \%)$ & $2(14 \%)$ & $5(36 \%)$ \\
\hline i135-i135 & 17 & $6(35 \%)$ & $4(24 \%)$ & $4(24 \%)$ & $3(18 \%)$ \\
\hline i $135-\mathrm{c} 45$ & 7 & $5(71 \%)$ & 0 & $1(14 \%)$ & $1(14 \%)$ \\
\hline NR-NR & 5 & $2(40 \%)$ & $1(20 \%)$ & 0 & $2(40 \%)$ \\
\hline Total & 82 & $33(40 \%)$ & $14(17 \%)$ & $11(13 \%)$ & $24(29 \%)$ \\
\hline \multicolumn{6}{|c|}{$\begin{array}{l}\text { Pairs consisting of two Purkinje cells in different zones } \\
\text { "Like pairs" }\end{array}$} \\
\hline $\mathrm{V} \wedge 1-\mathrm{VA} 2$ & 16 & $6(38 \%)$ & $3(19 \%)$ & $1(6 \%)$ & $6(38 \%)$ \\
\hline FVA-NVA & 14 & $3(21 \%)$ & $5(36 \%)$ & $1(7 \%)$ & $5(36 \%)$ \\
\hline Total & 30 & $9(30 \%)$ & $8(27 \%)$ & $2(7 \%)$ & $11(37 \%)$ \\
\hline \multicolumn{6}{|l|}{ "Unlike pairs" } \\
\hline VA-HA & 12 & 0 & $1(8 \%)$ & 0 & $11(92 \%)$ \\
\hline HA/VA-NR & 14 & 0 & 0 & 0 & $14(100 \%)$ \\
\hline Total & 26 & 0 & $1(4 \%)$ & 0 & $25(96 \%)$ \\
\hline
\end{tabular}

tion about an axis oriented at about $135^{\circ}$ ipsilateral azimuth (Simpson et al., 1981; Graf et al., 1988; Leonard et al., 1988). Since $\mathrm{cw}$ rotation about the axis at contra- $45^{\circ}$ azimuth is the same as ccw rotation about the axis at ipsi- $135^{\circ}$ azimuth (see Fig. 4), under binocular viewing conditions, the responses of ipsi- $135^{\circ}$ and contra- $45^{\circ}$ cells are indistinguishable. CS activity of Purkinje cells in the most medial zone of the ventral nodulus, zone NR, and zone $\mathrm{C} 2$ of the flocculus is not modulated by OKS (Kano et al., 1990a; De Zeeuw et al., in press b; Wylie et al., in press). Zone NR of the ventral nodulus receives $C F$ input from the $\beta$-subnucleus (beta) of the inferior olive (Balaban and Henry, 1988; Katayama and Nisimaru, 1988), and its cells are responsive to vestibular stimulation originating in the otoliths and vertical semicircular canals (Barmack et al., 1989, 1993; Shojaku et al., 1991; Barmack and Shojaku, 1992). Zone C2 of the flocculus receives its $\mathrm{CF}$ input from the rostral tip of the medial accessory olive (rMAO) (Tan et al., in press). It is not known what stimulus modulates CS activity in zone C2 (De Zeeuw et al., in press,b).

The vestibulocerebellum is an ideal structure to study the phenomenon of CS synchrony hecause the olivocortical projections have been precisely delineated, the zones can be identified with physiological criteria (OKS), and the messages carried by the CFs to each of the optokinetic zones is known. By recording from Purkinje cell pairs in the rabbit's vestibulocerebellum, we addressed the following questions: (1) Do Purkinje cells in the same zone with the same CS response properties show CS synchrony? (2) Do Purkinje cells in different zones, but having the same CS response properties (c.g., zones VA1 and VA2 of the nodulus) exhibit CS synchrony? (3) Do neurons in the same zone but having different $\mathrm{CS}$ response properties (i.e., c 45 cells i135 cells) exhibit CS synchrony? (4) Is the CS activity of nodulus Purkinje cells temporally related to the CS activity of flocculus Purkinje cells receiving $\mathrm{CF}$ input from the same subnucleus of the IO? (5) What is the effect of modulating CS activity by OKS on the strength of the temporal relationship?

\section{Materials and Methods}

Surgery. Experiments were performed on 24 Dutch-belted pigmented rabbits. Animals were initially anesthetized with a ketamine $(32 \mathrm{mg} /$ $\mathrm{kg}$ )-xylazine $(5 \mathrm{mg} / \mathrm{kg}$ )-acepromazine $(0.32 \mathrm{mg} / \mathrm{kg}$ ) cocktail (i.m.) and supplemental doses $(9 \mathrm{mg} / \mathrm{kg}$ ketamine; $2 \mathrm{mg} / \mathrm{kg}$ xylazine; $0.09 \mathrm{mg} / \mathrm{kg}$ acepromazine) were administered every 30-45 min. Rectal temperature was routinely measured, and the animals were placed on a heating pad to maintain body temperature at $37-39^{\circ} \mathrm{C}$. To penetrate the nodulus, a section of bone and underlying dura was removed from the back of the skull, exposing lobules VII, VIII, and IX of the cerebellar vermis. In some cases, the surface of the paramedian lobule was exposed to permit access to the flocculus.

Extracellular recording and optokinetic stimulation. Glass microelectrodes (2-3 M $\Omega$ ) filled with $2 \mathrm{M} \mathrm{NaCl}$ were used to record extracellular potentials. Initially, the approximate boundaries of the zones of the ventral nodulus were mapped out by making successive penetrations $300 \mu \mathrm{m}$ apart in the mediolateral direction. The zones were identified on the basis of CS modulation of Purkinje cells in response to OKS (Fig. 1). Once the zonal boundaries were determined, penetrations were made with pairs of electrodes. The two electrodes were independently manipulable and could be placed within the same zone or different zones in the ventral nodulus. In some cases, one electrode penetrated zone 2 or zone 4 of the flocculus and another electrode penetrated a VA zone in the nodulus.

The extracellular potentials were amplified and band-pass filtered (1$3000 \mathrm{~Hz}$; Tektronix AM 502). Purkinje cells were identified by the presence of the complex spike, which occurs spontaneously at about 1 spike/sec (Thach, 1967). Window discriminators (Frederick Haer \& Co.) produced standardized square wave pulses, each representing a single complex spike. Raw signals and discriminated pulse were displayed on

$\leftarrow$

Graf et al., 1988), which oscillated about either the vertical axis (right) or a horizontal axis oriented at $135^{\circ}$ ipsilateral azimuth $/ 45^{\circ}$ contralateral azimuth (left), as indicated in $B$. The planetarium oscillated at $0.1 \mathrm{~Hz}$ with a constant speed of $1 \% \mathrm{sec}$. The ordinate scale is the total number of spikes per $100 \mathrm{msec}$ bin cumulated over 10 cycles. The stimulus position profile is also shown in $C$. Abbreviations, rostral medial accessory olive $(r M A O)$, rostral dorsal cap $(r d c)$, ventrolateral outgrowth $(v l o)$, caudal dorsal cap $(c d c)$, nonresponsive $(N R)$, horizontal axis $(H A)$, vertical axis (VA, VA1, VA2). 

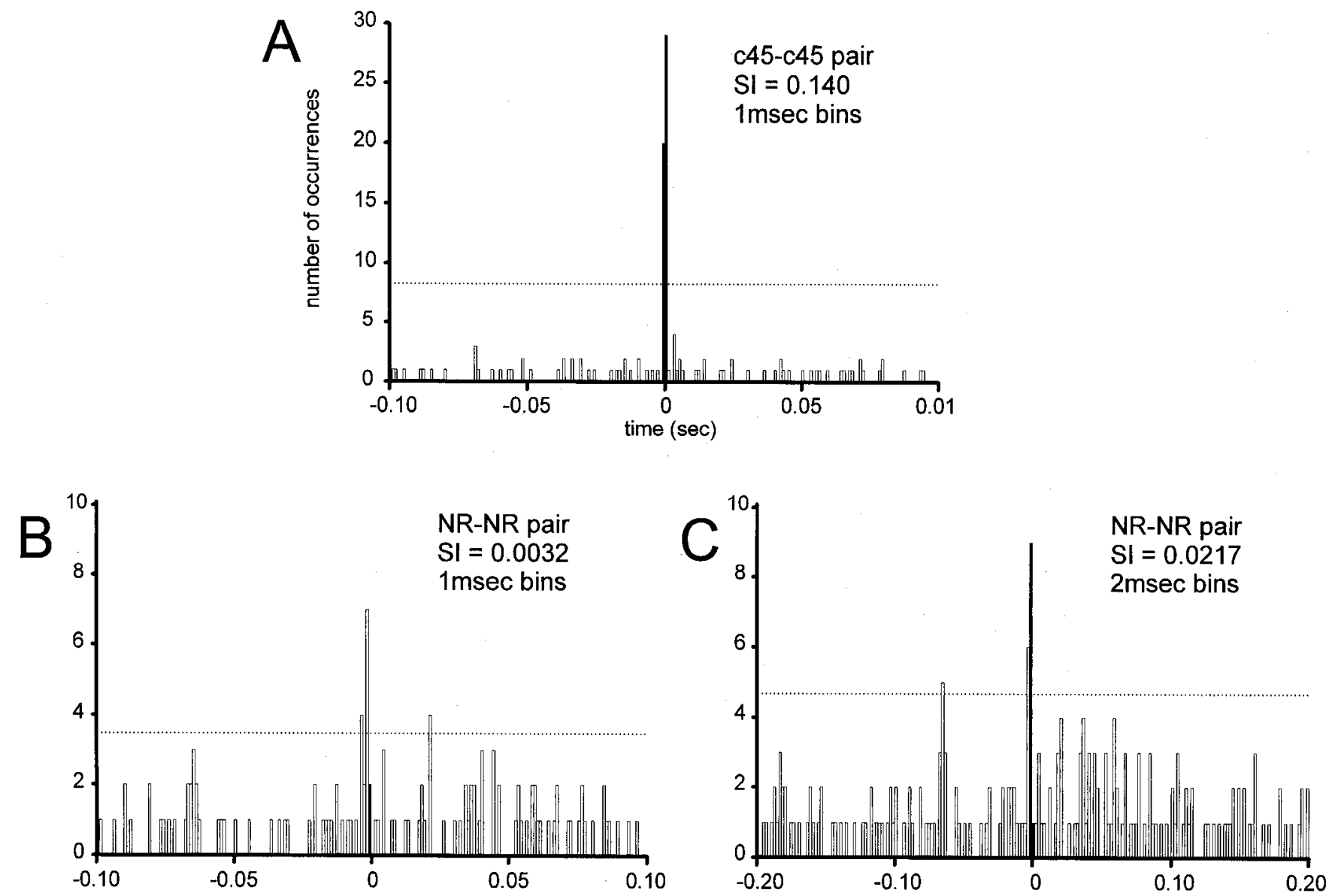

Figure 2. Synchronous CS activity of Purkinje cell pairs in the ventral nodulus. Cross-correlograms are shown for two Purkinje cell pairs that had a synchronous temporal relationship. Cross-correlograms were constructed and the temporal relationship was determined based on the three criteria described in the Materials and Methods section. The time-zero bins are shown in solid black, and the dotted horizontal line represents the mean +3 SD. The synchrony index $(S I)$ is also shown for each cell pair. In $A$, a time-zero bin met all three criteria. In $B$, a time-zero bin did not meet any of the criteria; however, when the same data was binned with 2 msec intervals $(C)$, a time-zero bin met all three criteria. Thus, by our definition, these two cells have a synchronous temporal relationship, displaying a tendency to fire within the same $2 \mathrm{msec}$, although not within the same msec. In fact, in the cross-correlogram in $B$, one neuron tends to fire $2 \mathrm{msec}$ before the other. The cell pair in $A$ showed a remarkably strong correlation, although there were four other pairs that showed a stronger synchronous relationship. The highest synchrony index observed was 0.5 . $A:$ time $=500 \mathrm{sec}$; cell 1, 268 spikes; cell 2, 430 spikes. $B$ and $C$ : time $=400 \mathrm{sec}$; cell 1, 345 spikes; cell 2, 427 spikes .

a storage oscilloscope (Tektronix 5115) and fed to an audio monitor (Grass AM5).

A pair of cells was recorded for 5-20 min during spontaneous activity and/or during OKS about the preferred axis (for pairs consisting of two cells with the same axis preference). The OKS was produced by a planetarium projector, which consists of a light source positioned in the center of a sphere that was pierced by numerous small holes. The sphere was oscillated $(0.025-0.1 \mathrm{H} \ell, 1 \% \mathrm{sec}$ constant speed) about an axis by a pen motor (MFE 54-150B), and the axis could be positioned at any orientation in space. The command signal for the pen motor was computer generated using ASYST sottware. The raw signals, discriminated pulses, and the command signal were stored on videotape with the aid of a multichannel Neuro-Corder (Neurodata DR-886). The pulses and command signal were also fed to a Cambridge Electronic Designs (CED) 1401 machine and peristimulus time histograms (PSTHs) were displayed on line with SPIKF 2 software.

Off-line data analysis. To assess the temporal relationship of a cell pair, cross-correlograms were constructed using existing routines in SPIKE2. The cross-correlogram is a continuous histogram of the time intervals between the occurrence of the CSs of the two different cells. Cross-correlograms were constructed using $1,2,5,10,20$, and $50 \mathrm{msec}$ bin widths and always included 200 bins, 100 on either side of the zerotime. (e.g., cross-correlograms containing $1 \mathrm{msec}$ bins were constructed from -100 to $+100 \mathrm{msec}$ ). The cross-correlograms contain two "timezero bins." One time-zero bin indicates the number of times that CS/ fires before CS2 within the given bin width, and the second indicates the number of times that CS1 fires after CS2 within the given bin width. Thus, to determine the number of times that two cells fire within $1 \mathrm{msec}$ of each other, the two time-zero bins of a $1 \mathrm{msec}$ bin width crosscorrelogram are summed.

The tendency of a neuron pair to fire within a given time period was determined as significant if one of the two time-zero bins was denoted as a peak. A time-zero bin was denoted as a peak if, (1) it had a value of at least $5,(2)$ it was the highest bin, and (3) it was at least 3 SD above the mean. The temporal relationship of the cell pair was designated according to the following definitions (see also Figs. 2, 3): (1) synchronous, time-zero peak in correlograms with 1 or $2 \mathrm{msec}$ bins; (2) perisynchronous, time-zero peak in correlograms with 5 or $10 \mathrm{msec}$ bins; (3) contemporaneous, time-zero peak in correlograms with 20 or $50 \mathrm{msec}$ bins; (4) unrelated, no time-zero peak in any correlograms.

To further quantify the temporal relationship of a cell pair the crosscorrelation coefficient was used as a synchrony index (SI) (Gerstein and Kiang, 1960; Sasaki et al., 1989; Sugihara et al., 1993; see Appendix). The SI was calculated for all bin widths except $50 \mathrm{msec}$. If available, cross-correlograms and SIs were obtained for spontancous activity, OKS in the "ON" direction (i.e., the direction resulting in CS excitation; see Fig. 1), and OKS in the "OFF" direction (i.e., the direction resulting in CS inhibition; see Fig. 1). Unless otherwise stated, the SIs and crosscorrelograms are based on the total (spontaneous + OKS) data available from the cell pair.

CS rhythmicity of individual Purkinje cells was examined by constructing autocorrelograms. Generally, $10 \mathrm{msec}$ bin widths were used 

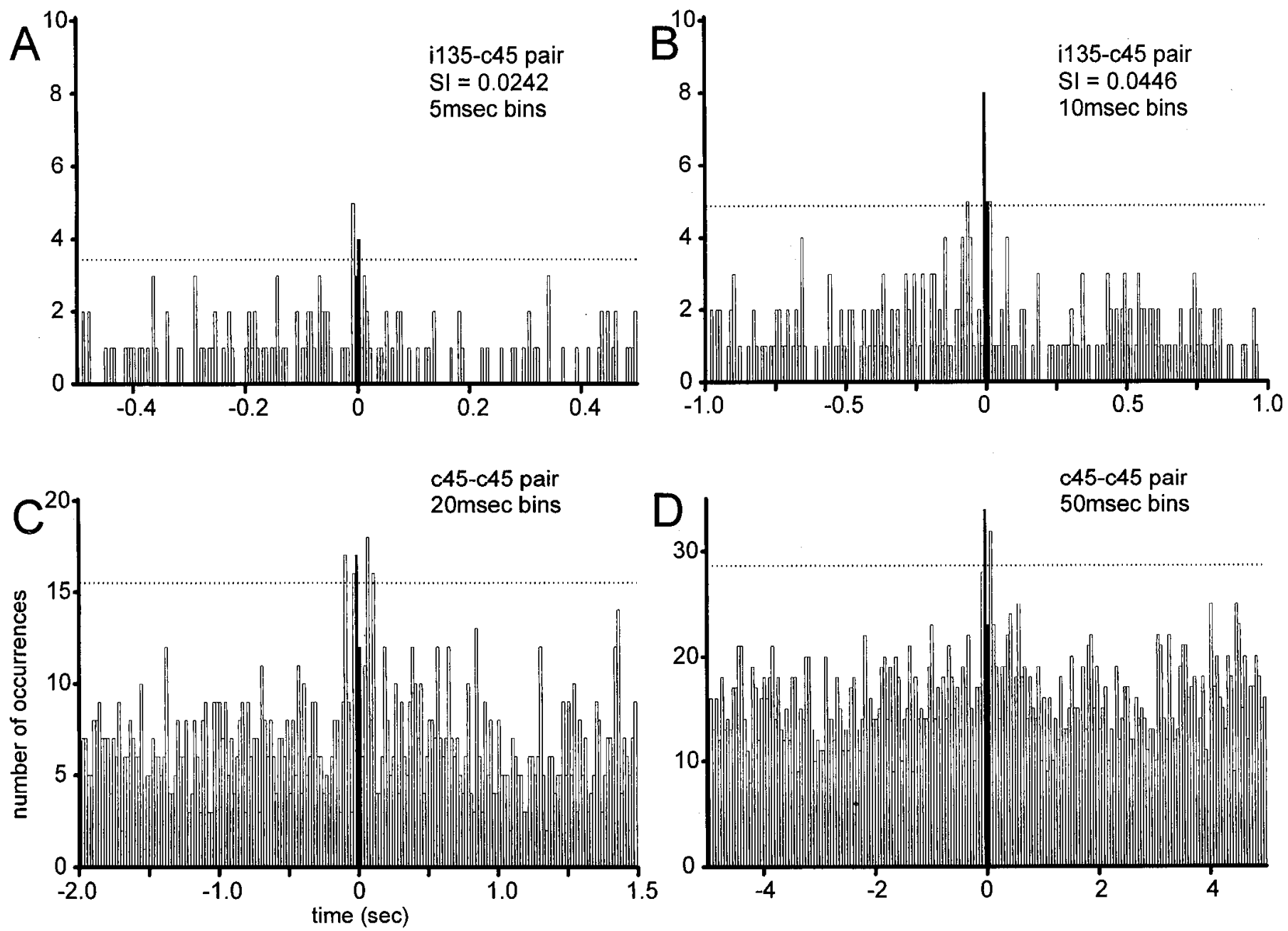

Figure 3. Perisynchronous and contemporaneous complex spike activity of Purkinje cell pairs. Cross-correlograms are shown for two Purkinje cell pairs that had perisynchronous $(A$ and $B)$ and contemporaneous $(C$ and $D)$ temporal relationships. In $A$, the cross-corrclogram is binned with $5 \mathrm{msec}$ intervals, but a time-zero bin is not the largest bin and does not contain at least five occurrences. When the same data is binned with 10 msec intervals, the criteria are met. Thus, this neuron pair showed at tendency to fire within $10 \mathrm{msec}$, but not within $5 \mathrm{msec}$. In $C$, a time-zero peak was greater than 5 , and greater than the mean $+3 \mathrm{SD}$, but was not the largest bin. In $D$, the same data is binned with 50 msec intervals and a time-zero bin met all three criteria. Thus, this neuron pair showed at tendency to fire within $50 \mathrm{msec}$, but not within $20 \mathrm{msec}$. $A$ and $B$ : time $=$ $600 \mathrm{sec}$; cell 1, 257 spikes; cell 2, 239 spikes. $C$ and $D$ : time $=1000 \mathrm{sec}$; cell 1, 454 spikes; cell 2, 691 spikes.

and 100 bins on each side of the time-zero bin were included. The frequency of rhythmic CS activity for a given neuron was determined from the time interval between peaks in the autocorrelogram and also by examining the power spectrum resulting from a fast Fourier transform (FFT) applied to the 'top' of the autocorrelogram. The FFT was only useful for those autocorrelograms that had two or more peaks on each side of time-zero (see Results). To analyze only the 'top' of the autocorrelogram, the period from 0 to $50 \mathrm{msec}$ was removed.

\section{Results}

The CS activity of 138 pairs of Purkinje cells was recorded. Of these, 124 pairs consisted of two nodulus neurons, while the remaining 14 pairs consisted of one cell in flocculus zone 2 or zone 4 and one cell in nodulus zone VA1 or VA2 (NVA-FVA pairs; see Table 1). Cross-correlograms were constructed for all cell pairs, and the temporal relationship of the pair was categorized as outlined in the Materials and Methods section. Crosscorrelograms of two synchronous cell pairs are shown in Figure 2 , and cross-correlograms of a perisynchronous pair and a contemporaneous pair are shown in Figure 3. Table 1 summarizes the temporal relations of all cell pairs.

\section{Pairs consisting of two neurons in the same zone}

The CS activity of 75 pairs consisting of two neurons from the same zone of the ventral nodulus, and having the same OKS response properties, was recorded [33 VA1-VA1 pairs, 6 VA2VA2 pairs, $14 \mathrm{c} 45$-c45 pairs (from zone $H A$ ), 17 il 35-i 135 pairs (from zone HA), and 5 NR-NR pairs; see Table 1]. Most ( $n=$ $52 ; 69.3 \%$ ) of these cell pairs showed some sort of temporally related CS activity. Twenty-eight (37.3\%) were synchronous, 14 (18.7\%) were perisynchronous, and $10(13.3 \%)$ were contemporaneous. Figure 2 shows cross-correlograms of a $\mathrm{c} 45-\mathrm{c} 45$ pair and an NR-NR pair that both showed a synchronous temporal relationship (see also Fig. $3 C, D$ ).

The CS activity of seven pairs of neurons consisting of one c45 and one i 135 neuron from the nodulus HA zone were also recorded (i135-c45 pairs). As previously mentioned, these Purkinje cell types respond best to OKS about a horizontal axis approximately perpendicular to the ipsilateral anterior canal, but they differ with respect to the olivary source of their CF input and their ocular dominance (see Fig. 4). Of seven i135-c45 pairs, 
A

ipsi-135 cell contralateral

viewing

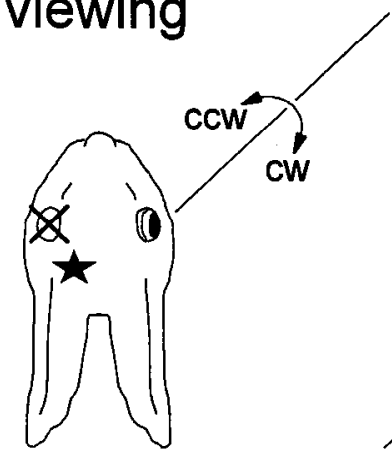

$D I=2.14$
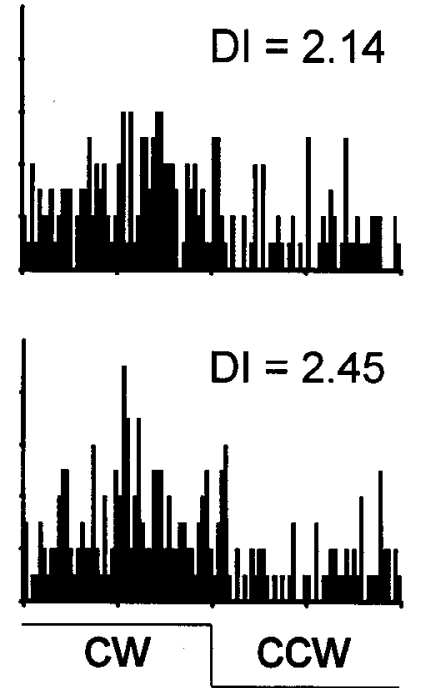

ipsilateral

viewing
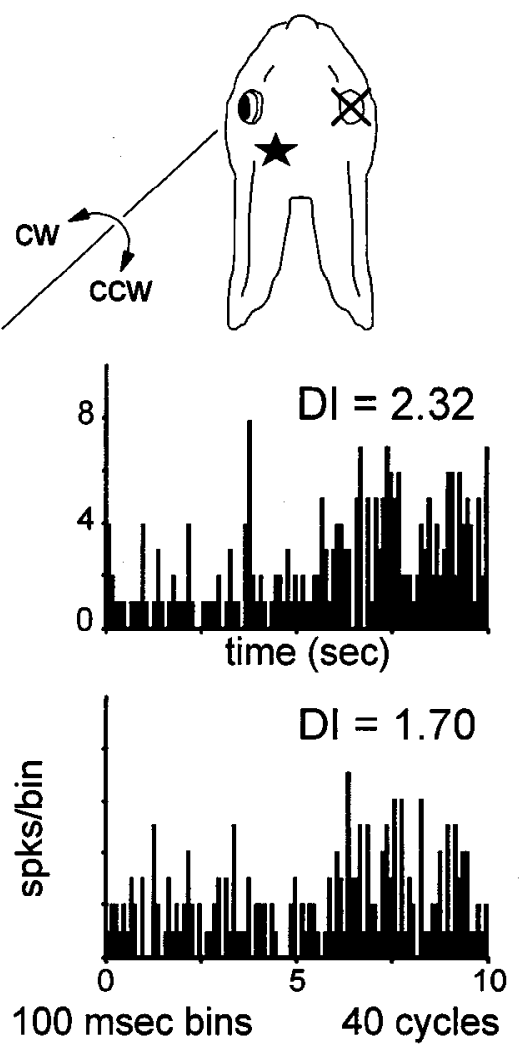

B

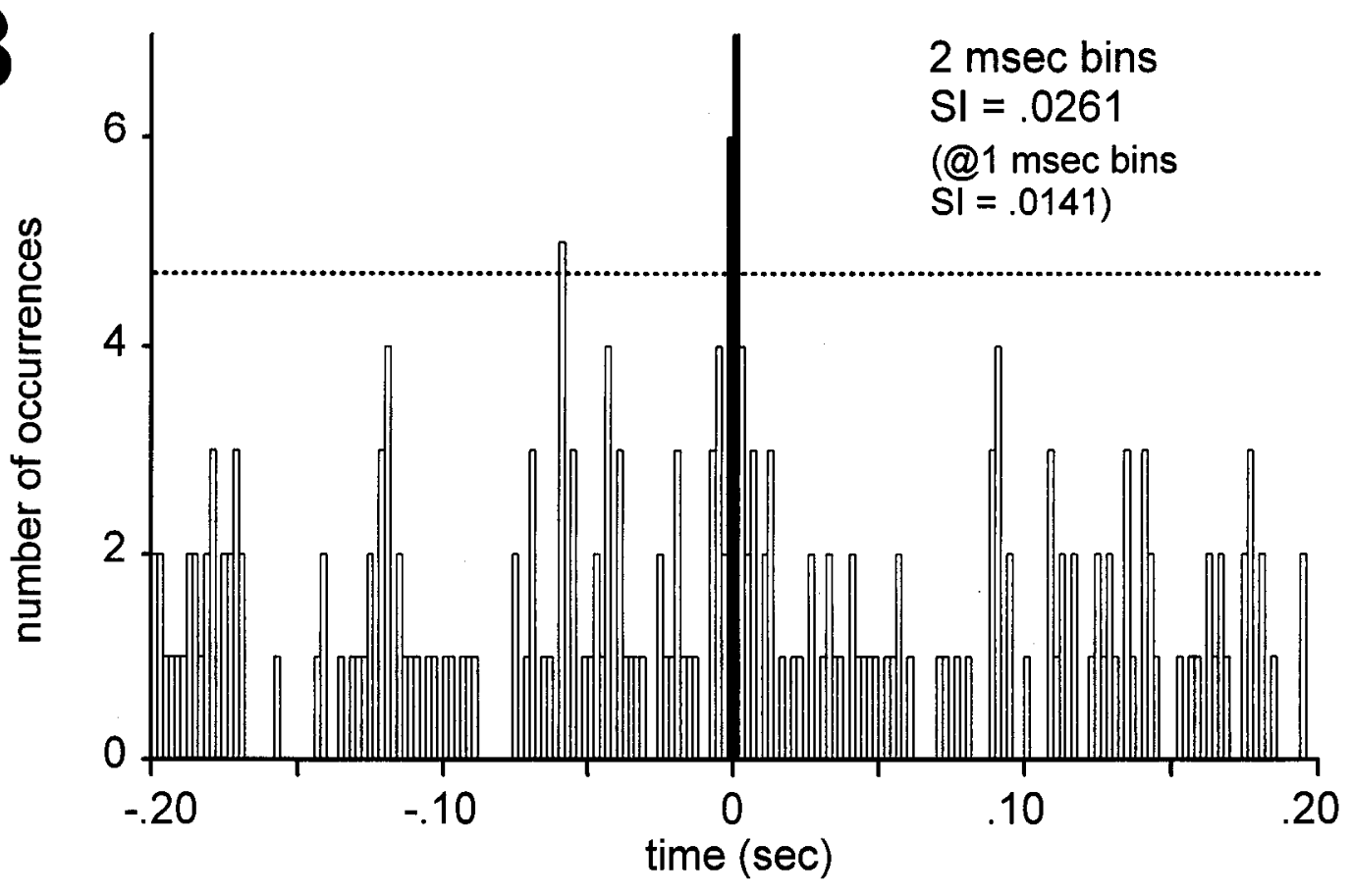

Figure 4. Synchronous CS activity of a contra $-45^{\circ}$ neuron and an ipsi- $135^{\circ}$ neuron in the HA zone of the ventral nodulus. $A$ shows the CS modulation of these two cell in response to OKS about the horizontal axis oriented at $45^{\circ}$ contralateral [ipsi (left) eye occluded] and to OKS about 
five $(71.4 \%)$ were synchronous, and one $(14.3 \%)$ was contemporaneous. Figure 4 shows the cross-correlogram of a cell pair consisting of an i135 cell and a c45 cell that were synchronous (see also Fig. $3 A, B$ ).

\section{Pairs consisting of neurons in different zones}

Recordings were made from 56 Purkinje cell pairs consisting of two cells from different zones (see Table 1). Of these, 16 pairs consisted of a cell from each of the VA zones in the ventral nodulus (VA1-VA2 pairs) and 14 pairs consisted of one cell in zone 2 or zone 4 of the flocculus and one cell in either zone VA1 or VA2 from the nodulus (FVA-NVA pairs). The remaining 26 pairs were called "unlike pairs" because they consisted of two neurons that did not have the same best-response axis to OKS. Twelve pairs consisted of two visually responsive cells, one from the HA zone and the other from either the VA1 or VA2 zone (VA-HA pairs). The remaining 14 pairs consisted of one Purkinje cell from the NR zone and a visually responsive cell from the adjacent VA1 zone $(n=11)$ or the HA zone $(n$ = 3) (NR-HA/VA pairs).

Similar to pairs consisting of two neurons from the same zone, the VA1-VA2 and NVA-FVA pairs showed a tendency to be temporally related. Of the 16 VA1-VA2 pairs, 6 were synchronous, 3 were perisynchronous, and 1 was contemporaneous. Of the 14 FVA-NVA pairs, 3 were synchronous, 5 were perisynchronous, and 1 was contemporaneous (see Fig. $6 B-D$ ).

In contrast, 25 of the 26 unlike pairs werc temporally unrelated. The exception was a VA-HA pair that was perisynchronous. If one considers all but the unlike pairs, of 112 Purkinje cell pairs, $77(68.8 \%)$ showed some sort of CS temporal relationship. Forty-two (37.5\%) were synchronous, $22(19.6 \%)$ were perisynchronous, and $13(11.6 \%)$ were contemporaneous.

\section{Groupwise comparison of synchrony indices}

The SI was calculated from the cross-correlograms of each Purkinje cell pair at bin widths of 1, 2, 5, 10, and $20 \mathrm{msec}$. Figure 5 shows histograms of the mean SIs, grouped according to the type of cell pair, for $2(A)$ and $10(B)$ msec bin widths. All groups were compared pairwise using Mann-Whitney $U$ tests. In $A$, with the exception of the $\mathrm{c} 45-\mathrm{c} 45$ and NR-NR groups, the SIs of all groups were significantly greater than the SIs of both groups of "unlike pairs" (onc-tailed tests). In $B$, the SIs of all groups were significantly greater than the SIs of the VA/HA-NR group, and the SIs of all groups except the NR-NR group were significantly greater than the VA-HA pairs. At both bin widths, the SIs of the VA-HA pairs and VA/HA-NR pairs were not significantly different (two-tailed tests), and there were no significant differences between any other two groups (two-tailed tests).

\section{Effect of optokinetic stimulation on the strength of the temporal relationship}

Recordings were made from 88 neuron pairs during OKS about the preferred axis in the "ON" and "OFF" directions, and from 53 of these pairs recordings were also ohtained during spontaneous activity. Cross-correlograms were constructed and SIs were calculated for each cell pair under each condition. The effect of OKS on the strength of the temporal relationship was determined, as outlined in Figure 6. SI ratios were calculated for each comparison [e.g., $(\mathrm{ON}-\mathrm{OFF}) /(\mathrm{ON}+\mathrm{OFF})]$, and a $t$ test was performed versus the null hypothesis that there was no difference [i.e., $\mathrm{H}_{0}=(A-B) /(A+B)=0$ ]. Note that (1) the SIs during OKS in the "ON" direction were significantly greater than during spontaneous activity for all bin widths, (2) the SIs during the "OFF" direction were significantly greater than during spontaneous activity only for those calculated from the 10 msec bins, and (3) the SIs during OKS in the "ON" direction was significantly greater than the SIs during the "OFF" direction for those calculated from $1 \mathrm{msec}$ bins. Figure $6 B-E$ shows data from an NVA-FVA pair. Cross-correlograms (1 msec bins) are shown for OKS in the "ON" direction $(B)$, "OFF" direction $(C)$, and during spontaneous activity $(D)$. Figure $6 E$ shows the ratio comparisons. Typical of our sample, the temporal relationship of this cell pair was strongest during OKS in the "ON" direction, and weakest during spontaneous activity.

\section{Rhythmicity of complex spike activity of individual Purkinje cells}

The rhythmic firing of Purkinje cell CSs was examined by constructing autocorrelograms of 114 nodulus Purkinje cells. Of these, $36(31.6 \%)$ showed a clear rhythmic firing pattern, as revealed by peaks in the autocorrelograms. The autocorrelograms of four cells are shown in Figure 7 . For the 36 cells, one to six peaks on each side of the correlogram were apparent (mean $=2.4$ peaks). While most $(25)$ had two or more peaks (Fig. $7 A-C$ ), 11 had only one peak (Fig. $7 D$ ). (Cells showing a single peak in the autocorrelogram would accurately be described as producing pairs of action potentials separated by a characteristic time interval.) As shown in the right panels of Figure 7, fast Fourier transforms were applied to the tops of the autocorrelograms displaying more than one peak. The resultant power spectrum showed a peak corresponding to the characteristic frequency of the cell. The characteristic frequency of these 36 neurons averaged $8 \mathrm{~Hz}$ (range $2.5-12.5 \mathrm{~Hz}$ ). Rhythmic activity of an individual neuron was independent of the temporal relationship of a recorded neuron pair. That is, for a pair showing a synchronous temporal relationship, one, both, or neither of the neurons may have been rhythmic.

\section{Discussion}

Purkinje cells in the same zone

We categorized the temporal relationship as either synchronous (within 1-2 msec), perisynchronous (5-10 msec), or contem-

$\leftarrow$

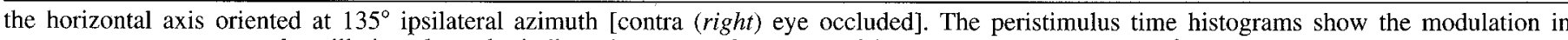

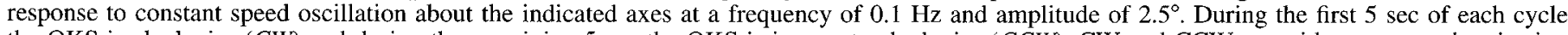

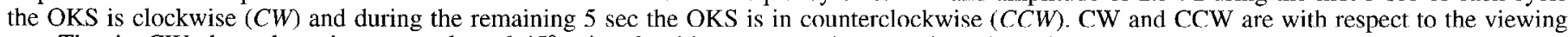

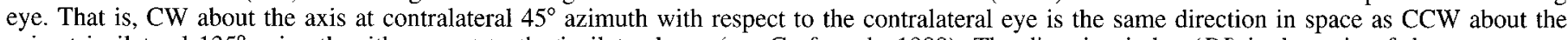

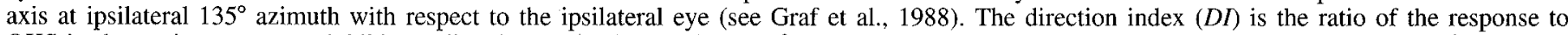

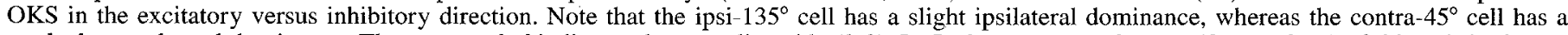

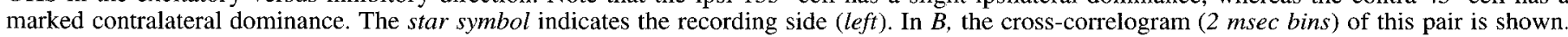
Time $=850 \mathrm{sec}$; cell 1, 635 spikes; cell 2, 335 spikes. 

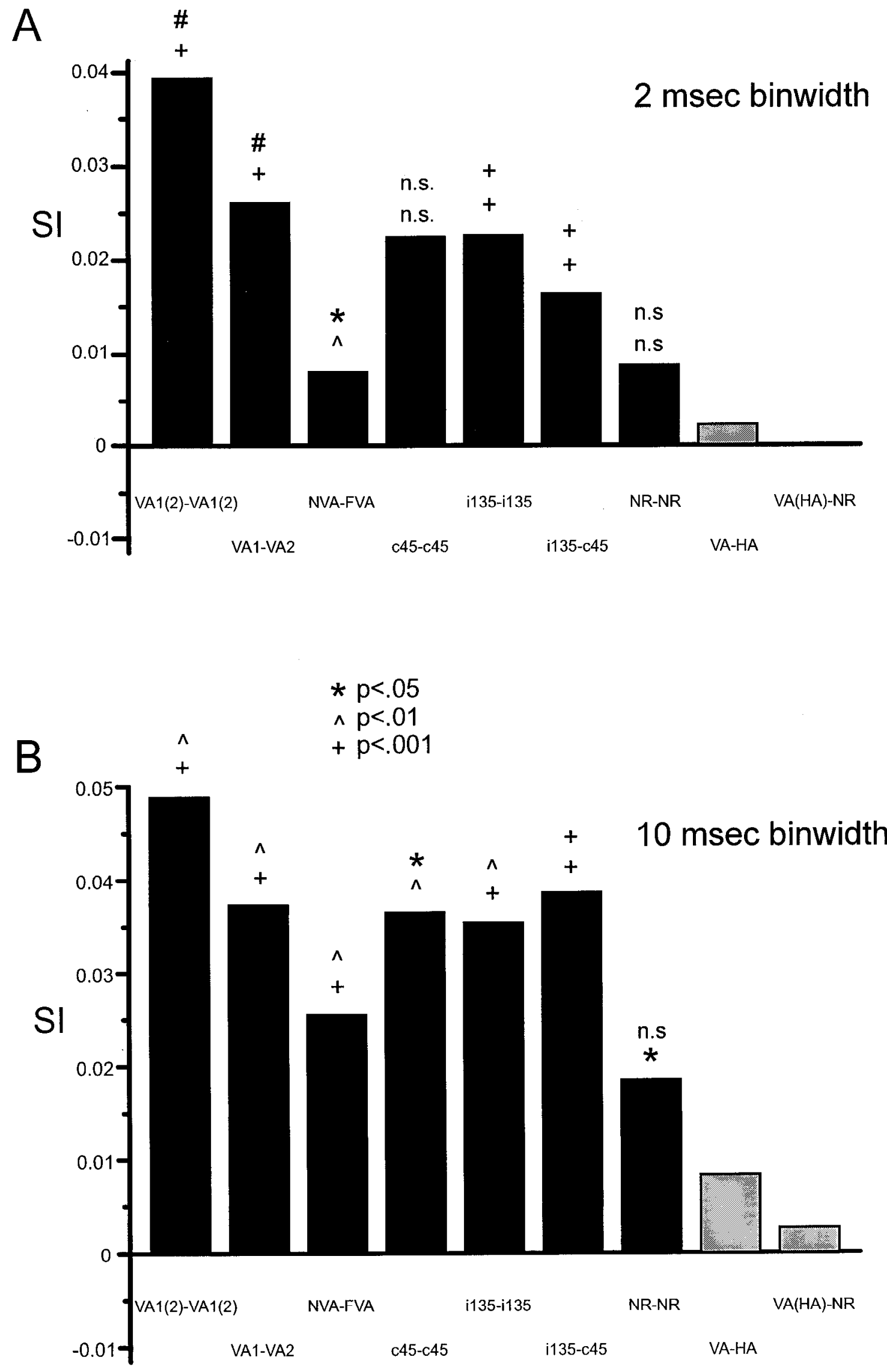

Figure 5. Average cross-correlation coefficients of the CS activity of Purkinje cell pairs in the vestibulocerebellum. The average synchrony indices (SIS) for each group were calculated from the cross-correlograms, and are shown in histogram form for those binned at 2 and $10 \mathrm{msec}(A$ and $B$, respectively). Groups were compared using the Mann-Whitney $U$ test. Above each solid bar, the upper and lower symbols indicate the significance 
poraneous (20-50 msec), because previous studies describing "synchronous" CS activity were clearly describing different relationships. For example, Llinás and colleagues (Llinás and Sasaki, 1989; Sasaki et al., 1989; Sugihara et al., 1993) describe synchronous activity as occurring within a few milliseconds, whereas Lou and Bloedel (1986, 1992) describe "synchronous" activity in relation to a time window on the order of tens of milliseconds. It is noteworthy that, on some occasions, a neuron pair could show a 'mixture' of two relationships. For example, for the pair in Figure $6 B$, there are several occurrences of firing within $1 \mathrm{msec}$, but also a significant number of occurrences within $10 \mathrm{msec}$. Thus, there appears to be a "synchronous" tendency superimposed upon a broader "perisynchronous" relationship. In such cases, we maintained the three-point criterion and described this relationship as synchronous.

In the present study, we have shown that the complex spike activity of Purkinjc cclls in the same zone of the ventral nodulus is temporally related. Of 82 pairs, $40 \%$ were synchronous, $17 \%$ were perisynchronous, and $13 \%$ were contemporaneous. This confirms the observations of Bell and Kawasaki (1972) and Llinás and colleagues (Llinás and Sasaki, 1989; Sasaki et al., 1989; Sugihara et al., 1993) who found that the CS synchrony of Purkinje cells was strongest in the sagittal plane, but progressively decreased as the mediolateral distance between a pair increased. Whereas these researchers described this pattern of CS synchrony as a 'spatial' phenomenon, we describe CS synchrony with respect to functional properties of the zones. Purkinje cells in the same physiologically identified zone show CS synchrony.

The HA zones in the flocculus and ventral nodulus contain contra- $45^{\circ}$ and ipsi- $135^{\circ}$ Purkinje cells, which receive $\mathrm{CF}$ input from the rdc and vlo, respectively. Nevertheless, in the present study we showed that c45-i135 pairs were temporally related. Of seven such pairs, five were synchronous and one was perisynchronous. Since CS synchrony is most likely the result of gap junctions between IO neurons (Lang, 1989, 1990; Llinás and Sasaki, 1989; Sasaki et al., 1989), the present study suggests that different, although contiguous, olivary subnuclei (rdc and vlo) may be electrotonically coupled.

\section{Vertical axis neurons in different zones}

In the present study, we showed that Purkinje cells in the VA1 and VA2 zones were temporally related. Of 16 VA1-VA2 pairs, 6 were synchronous, 3 were perisynchronous, and 1 was contemporaneous. Moreover, we found that flocculus VA neurons were temporally related with VA neurons in the ventral nodulus. Of 14 NVA-FVA pairs, 3 were synchronous, 5 were perisynchronous, and 1 was contemporaneous. At first glance, this finding is not surprising given that these zones receive input from the same subnucleus of the IO, the cde (Balaban and Henry, 1988; Katayama and Nisimaru, 1988; Tan et al., in press). In fact, some CFs branch and innervate both the flocculus and the nodulus (Takeda and Maekawa, 1989a,b). However, synchronous CS activity between Purkinje cells in these spatially separated VA zones is remarkable when one considers that the CFs to different zones are likely of different lengths. Sugihara et al. (1993) have reported that CFs of different lengths in rats have uniform conduction times (but see Aggelopoulous et al., 1994).
They also showed that the longer branches of branching olivocerebellar fibers tended to have thicker diameters than the shorter branches.

Functionally, we are not sure what the different VA axis zones in the ventral nodulus and flocculus represent. One problem is that the ventral nodulus is rarely studied in isolation, and often the ventral and dorsal nodulus are grouped with the ventral uvula (Nagao, 1983; Waespe et al., 1985). In rabbits, flocculectomy results in a phase lag of the vestibulocular reflex (Ito et al, 1982; Nagao, 1983), whereas nodulectomy results in a phase lead (Nagao, 1983). Recent studies in primates have concluded that, in broad terms, the nodulus and ventral uvula are involved in the control of the velocity storage mechanism, whereas the flocculus is important in controlling the gain of the vestibulo-ocular and optokinetic reflexes (Waespe et al., 1983, 1985; Waespe and Hess, 1987; Cohen et al., 1992). In this regard, the VA zones in the nodulus and flocculus may be establishing timing information necessary for coordinating these different components of the compensatory response.

\section{Effect of optokinetic stimulation on the strength of CS temporal relations}

A characteristic feature of Purkinje cells in the VA and HA zones of the flocculus and nodulus is the CS modulation that occurs in response to rotational OKS about a particular axis (Simpson et al., 1981; Graf et al., 1988; Kano et al., 1990a,b; Kusonoki et al., 1990; De Zeeuw et al., in press b; Wylie et al., in press). In the present study, we have shown that temporally related CS activity is also a characteristic feature of Purkinje cells within the same zone. Moreover, we have shown a relationship between these two characteristics. We found that the cross-correlation coefficient was slightly (about 20\%), but significantly higher during $\mathrm{OKS}$ in the "ON" direction versus spontaneous activity when calculated from the cross-correlograms constructed at all five bin widths. This is the first demonstration in the vestibulocerebellum that sensory stimulation can increase temporally related CS activity. Differences between "OFF" and spontaneous activity were less consistent and somewhat curious. The SI was higher for "OFF" than spontaneous, but this difference was only significant for those SIs calculated at the $10 \mathrm{msec}$ bin width.

We believe that the effect of OKS on the temporal relationship of Purkinje cells will be larger and more consistent in an alert preparation for two reasons. First, in the anesthetized rabbit, eye movements do not occur, whereas the alert animal will make compensatory eye movements in response to visual and vestibular stimulation. Welsh et al. (1993; personal communication) have noted that CS synchrony in crus 2 increases during movement. Second, Lang et al. (1989, 1990) have shown that CS synchrony is affected by manipulation of the cerebellar nucleus neurons that provide the GABAergic innervation to the subnucleus of the IO giving rise to the climbing fiber innervation of the corresponding cerebellar zone (De Zeeuw et al., 1989). Destruction of the GABAergic input results in an increase in the CS synchrony. The GABAergic input to the dc and vlo is from the prepositus hypoglossi (De Zeeuw et al., 1993), the ventral dentate nucleus, and the dorsal group y (De Zeeuw et al., 1994). 

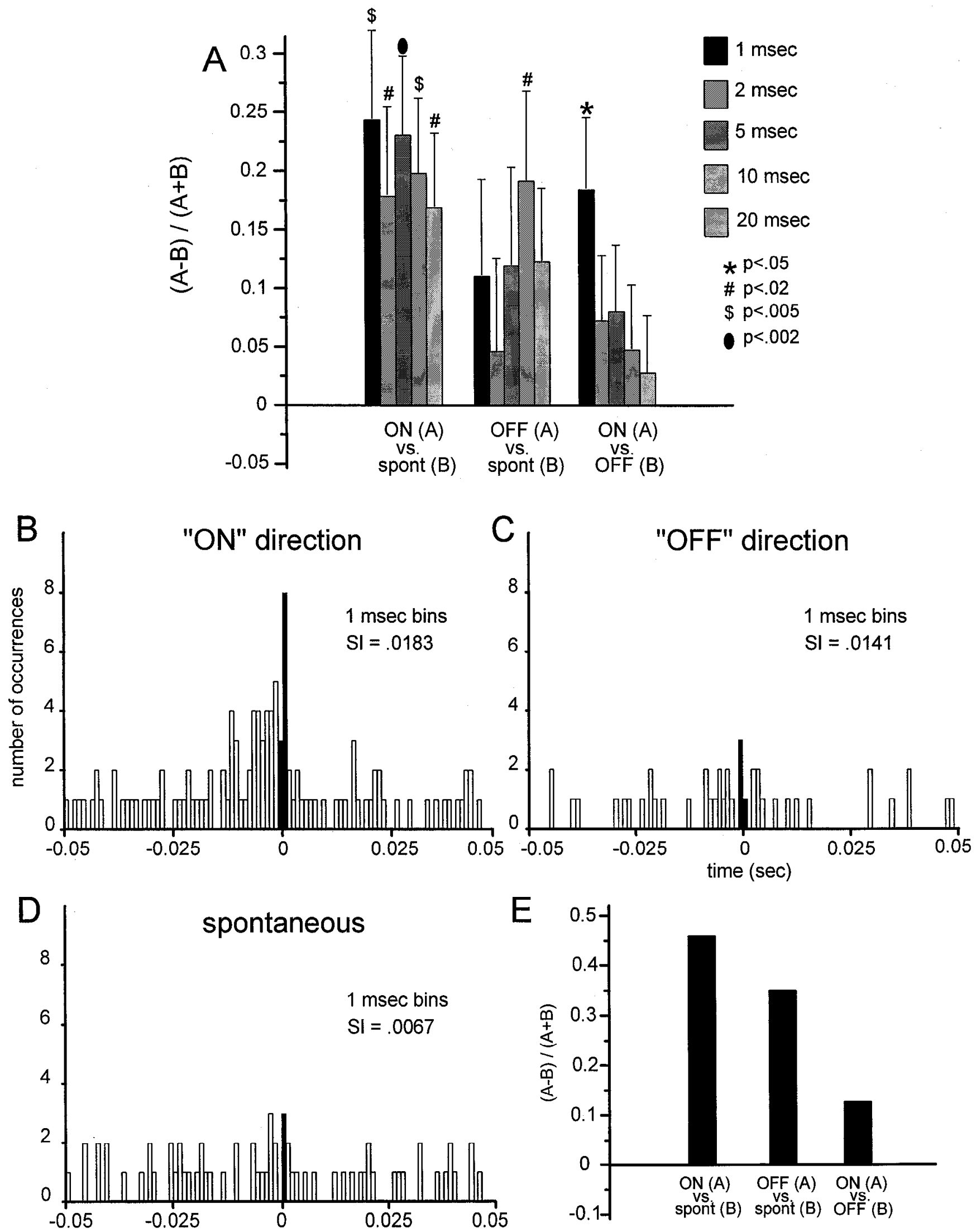

Figure 6. Effect of optokinetic stimulation on the temporal relationship of Purkinje cell pairs. A, The SI was calculated from the cross-correlograms of cell pairs that were recorded during optokinetic stimulation (excitatory and inhibitory) and spontaneous activity. To compare these three conditions, a ratio was calculated for each cell pair $[(A-B) /(A+B)]$, and a $t$ test was performed versus the $H_{0}$ that there was no difference [i.e., $(A-B) /$ $(A+B)=0$ ]. This histogram shows the means of the ratio for "ON" versus spontaneous, "OFF" versus spontaneous and "ON" vs. "OFF" for five different bin widths. The error bars represent +1 SE. (Before transformation, any SI $<0.0001$ was assigned a value of 0.0001 .) $B-E$ show a typical example of the effect of OKS on the strength of the temporal relationship of a Purkinje cell pair consisting of a nodulus VA1 cell and a 

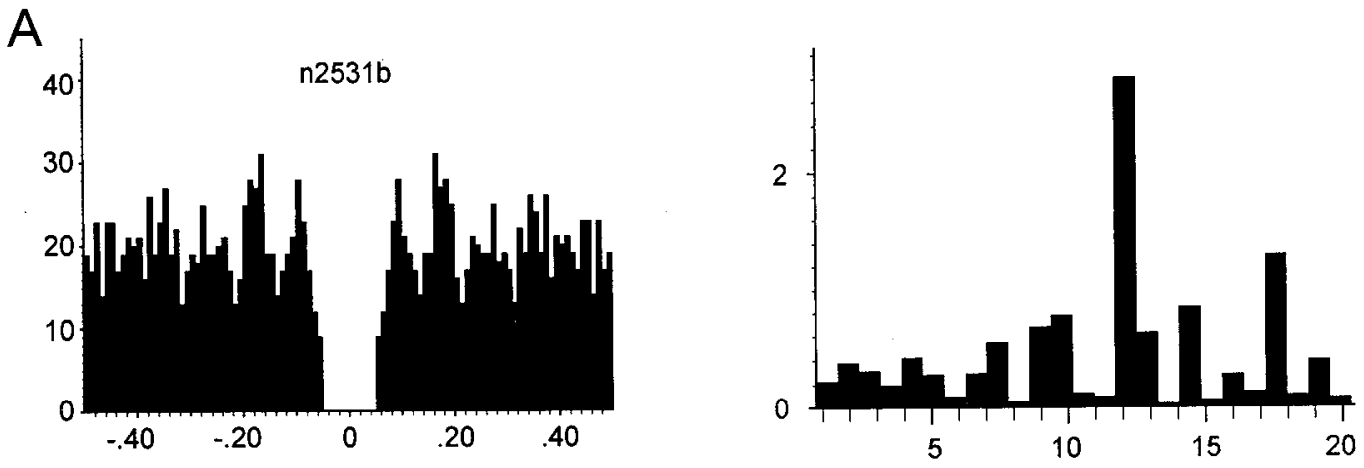

B
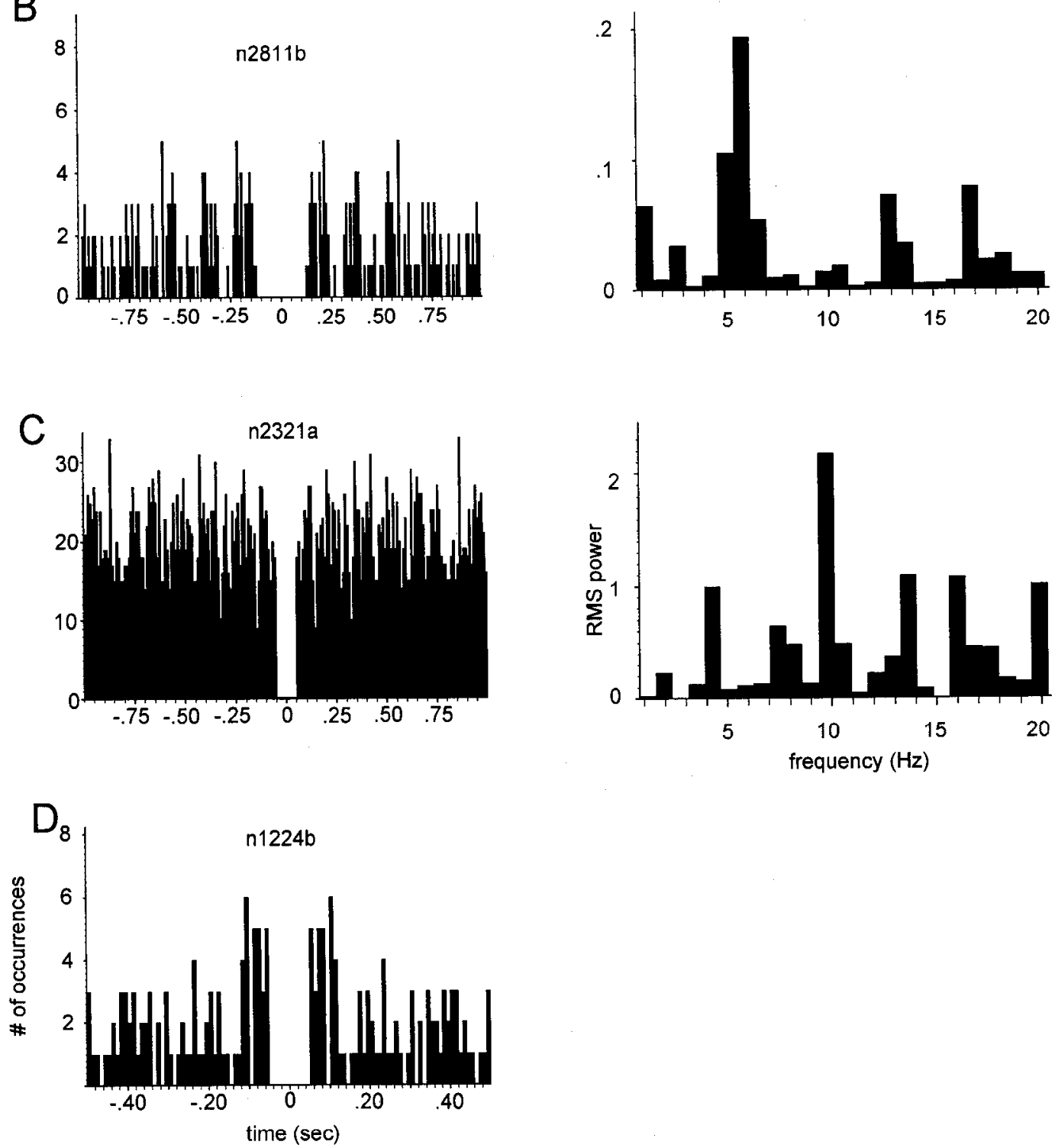

Figure 7. Complex spike rhythmicity of Purkinje cells. On the left the auto-correlograms of four Purkinje cells considered to be rhythmic are shown. The central peak (time-zero) was removed. On each side of the correlogram there are two to four peaks in $A$, three peaks in $B$, five to six peaks in $C$, and a single peak in $D$. The characteristic frequency of a cell was calculated by taking the inverse of the time between peaks. On the right, the fast Fourier transforms applied to the tops of the correlograms displaying more than one peak $(A, B$, and $C$ ) are shown. RMS (root mean squared) power is shown as a function of frequency. In these histograms, the $n$th bin is at the frequency $n / 1.28 \mathrm{~Hz}$. That is, successive bins are incremented by $0.78 \mathrm{~Hz}$. Note that peaks are seen at about $12,5-6$, and $10 \mathrm{~Hz}$ in $A, B$, and $C$, respectively.

flocculus VA cell that were synchronously related. Cross-correlograms ( 1 msec bins) constructed from recordings during OKS in the "ON" direction $(B)$, OKS in the "OFF" direction $(C)$, and spontaneous activity $(D)$ are shown, and the SIs are indicated. $E$ shows the ratios for this cell pair at this bin width. $B$ : time $=500 \mathrm{sec}$; cell 1,840 spikes; cell 2, 374 spikes. $C$ : time $=500 \mathrm{sec}$; cell 1, 402 spikes; cell 2 , 173 spikes. $D:$ time $=500$ sec; cell 1, 566 spikes; cell 2,239 spikes. 
Many of these GABAergic terminals synapse onto dendritic elements linked by gap junctions, which are thought to be responsible for the electrotonic coupling (Llinas et al., 1974; Sotello et al., 1974; De Zeeuw et al., 1989). Neurons in the prepositus and dorsal y are modulated during visual and vestibular stimulation in alert preparations (Lopez-Barneo et al., 1982; Chubb et al., 1984; Escudero et al., 1992; McFarland and Fuchs, 1992; Partsalis et al., 1993) and this modulation may result in stronger CS synchrony.

\section{Appendix}

Calculation of synchrony index

The standard cross-correlation coefficient was used as a synchrony index $(\mathrm{SI})$ :

$$
\mathrm{SI}=r=\frac{\mathrm{SS}_{x y}}{\sqrt{\mathrm{SS}_{x x} \mathrm{SS}_{y y}}},
$$

where

$$
\begin{aligned}
& \mathrm{SS}_{x x}=\sum X^{2}-\frac{\left(\sum X\right)^{2}}{n}, \quad \mathrm{SS}_{y y}=\sum Y^{2}-\frac{\left(\sum Y\right)^{2}}{n}, \\
& \mathrm{SS}_{x y}=\sum X Y-\frac{\left(\sum X\right)\left(\sum Y\right)}{n} .
\end{aligned}
$$

For an epoch time of duration $T$ sec, the spike trains of the two cells, $X(t)$ and $Y(t)$, are divided into $n$ bins (T/bin width) ( $i$ $=1 \ldots n) . X(t)$ and $Y(t)$ have the value of 1 (CS present) or 0 (CS not present) at time $(t)$. If cell $X$ fires $a$ times and cell $Y$ fires $b$ times during the epoch $T$, and on $c$ occasions both cells fire within the same bin, then

$$
\sum_{i=1}^{n} X_{i}=\sum_{i=1}^{n} X_{i}^{2}=a, \quad \sum_{i=1}^{n} Y_{i}=\sum_{i=1}^{n} Y_{i}^{2}=b, \quad \sum_{i=1}^{n} X_{i} Y_{i}=c .
$$

Consequently,

$$
\mathrm{SS}_{x x}=a-\frac{a^{2}}{n}, \quad \mathrm{SS}_{y y}=b-\frac{b^{2}}{n}, \quad \mathrm{SS}_{x y}=c-\frac{a h}{n},
$$

and

$$
\mathrm{SI}=\frac{\left(c-\frac{a b}{n}\right)}{\sqrt{a\left(1-\frac{a}{n}\right) b\left(1-\frac{b}{n}\right)}} .
$$

To illustrate the effect of absolute firing rate on the SI, suppose cell $X$ fires $600(a)$ times and cell $Y$ fires $400(b)$ times in 500 sec. Further suppose that for the $1 \mathrm{msec}$ cross-correlogram the sum of the two time-zero bins is $50(\mathrm{c})$. Because the two timezero bins were summed, the bin width is $0.002 \mathrm{sec}$ and therefore $n=250000$ :

$$
\begin{aligned}
& S I=\frac{50-\frac{(600)(400)}{250000}}{\sqrt{600\left(1-\frac{600}{250000}\right) 400\left(1-\frac{400}{250000}\right)}} \\
& S I=0.1003 .
\end{aligned}
$$

Suppose that the two cells fire at half this frequency. If ccll $X$ fires $300(a)$ times and cell $Y$ fires 200 times $(b)$ in $500 \mathrm{sec}$, and for the $1 \mathrm{msec}$ cross-correlogram the sum of the two time-zero bins is $25(c)$, then

$$
\begin{aligned}
& \mathrm{SI}=\frac{25-\frac{(300)(200)}{250000}}{\sqrt{300\left(1-\frac{300}{250000}\right) 200\left(1-\frac{200}{250000}\right)}} \\
& \text { SI }=0.1011 .
\end{aligned}
$$

The SI is only slightly higher in the second scenario with the lower firing rates. This is because the number of bins in which both cells do not fire is higher, which contributes to the correlation.

\section{References}

Aggelopoulous AC, Duke C, Edgley SA (1994) Non-uniform conduction time in the olivocerebellar pathway in the anaesthetized cat. $\mathrm{J}$ Physiol (Lond) 476.P:26-27.

Balaban CD, Henry RT (1988) Zonal organization of olivo-nodulus projections in albino rabbits. Neurosci Res 5:409-423.

Barmack NH, Shojaku H (1992) Representation of a postural coordinate system in the nodulus of the rabbit cerebellum by vestibular climbing fiber signals. In: Vestibular control of eye, head and body movements (Shimazu H, Shimoda Y, eds), pp 331-338. Basel/Tokyo: Karger/Japan Scientific Societies.

Barmack NH, Mugnaini E, Nelson BJ (1989) Vestibularly-evoked activity of single neurons in the beta nucleus of the inferior olive. In: The olivocerebellar system in motor control (Strata P, ed), pp 313322. Berlin: Springer.

Barmack NH, Fagerson M, Fredette BJ, Mugnaini E, Shoiaku H (1993) Activity of neurons in the beta nucleus of the inferior olive of the rabbit evoked by natural vestibular stimulation. Exp Brain Res 94: $203-215$

Bell CC, Grimm RJ (1969) Discharge properties of Purkinje cells recorded on single and double microelectrodes. J Neurophysiol 32: 1044-1055.

Bell CC, Kawasaki T (1972) Relations among climbing fibre responses of nearby Purkinje cells. J Neurophysiol 35:155-169.

Chubb MC, Fuchs AF, Scudder CA (1984) Neuron aclivity in monkey vestibular nuclei during vertical stimulation and eye movements. $\mathbf{J}$ Neurophysiol 52:724-742.

Cohen H, Cohen B, Raphan T, Waespe W (1992) Habituation and adaptation of the vestibuloocular reflex: a model of differential control by the vestibulocerebellum. Exp Brain Res 90:526-538.

De Zeeuw CI, Holstege JC, Ruigrok TJH, Voogd J (1989) Ultrastructural study of the GABAergic, cellular, and mesodiencephalic innervation of the cat medial accessory olive: anterograde tracing combined with immunocytochemistry. J Comp Neurol 284:12-35.

De Zeeuw CI, Wentzel P, Mugnaini E (1993) Fine structure of the dorsal cap of the inferior olive and its GABAergic and non-GABAergic input from the nucleus prepositus hypoglossi in rat and rabbit. J Comp Neurol 327:63-82.

De Zeeuw CI, Gerrits NM, Voogd J, Leonard CS, Simpson JI (1994) The rostral dorsal cap and ventrolateral outgrowth of the rabbit inferior olive receive a GABAergic input from dorsal group y and the ventral dentate nucleus. J Comp Neurol 341:420-432.

De Zeeuw CI, Hertzberg EL, Mugnaini E (in press,a) The dendritic lamellar body: a new neuronal organelle putatively associated with dendrodendritic gap junctions. J Neurosci, in press.

De Zeeuw CI, Wylie DR, DiGiorgi PL, Simpson JI (in press,b) Projections of individual Purkinje cells of identified zones in the flocculus to the vestibular and cerebellar nuclei in the rabbit. J Comp Neurol, in press.

Escudero M, de la Cruz RR, Delgado-Garcia JM (1992) A physiological study of vestibular and prepositus hypoglossi neurones projecting to the abducens nucleus in the alert cat. $\mathbf{J}$ Physiol (Lond) 458:539560 .

Gerstein GL, Kiang WY (1960) An approach to the quantitative analysis of equations of electrophysiological data from single neurons. Biophys J 1:15-28.

Graf W, Simpson JI, Leonard CS (1988) Spatial organization of visual 
messages to the rabbit's cerebellar flocculus. II. Complex and simple spike responses of Purkinje cells. J Neurophysiol 60:2091-2121.

Groenewegen HJ, Voogd J, Freedman SL (1979) The parasagittal zonation within the olivocerebellar projection. II. Climbing fibre distribution in the intermediate and hemispheric parts of the cat cerebellum. J Comp Neurol 183:551-602.

Ito M, Jastreboff PJ, Miyashita Y (1982) Specific effects of unilateral lesions in the flocculus upon eye movements in albino rabbits. Exp Brain Res 45:233-242.

Kano M, Kano M-S, Kusonoki M, Maekawa K (1990a) Nature of optokinetic response and zonal organization of climbing fiber afferents in the vestibulocerebellum of the pigmented rabbit. II. The nodulus. Exp Brain Res 80:238-251.

Kano M-S, Kano M, Maekawa K (1990b) Receptive field organization of climbing fiber afferents responding to optokinetic stimulation in the cerebellar nodulus and flocculus of the pigmented rabbit. Exp Brain Res 82:499-512.

Katayama S, Nisimaru N (1988) Parasagittal zonal pattern of olivonodular projections in rabbit cerebellum. Neurosci Res 5:424-438.

Kusonoki M, Kano M, Kano, M-S, Maekawa K (1990) Nature of optokinetic response and zonal organization of climbing fiber afferents in the vestibulocerebellum of the pigmented rabbit. I. The flocculus. Exp Brain Res 80:225-237.

Lang EJ, Chou M, Sugihara I, Llinäs R (1989) Intraolivary injection of picrotoxin causes reorganization of complex spike activity. Soc Neurosci Abstr 15:179.

Lang EJ, Sugihara I, Llinás R (1990) Lesions of the cerebellar nuclei, but not of the mesencephalic structures, alters the spatial pattern of complex spike synchronicity as demonstrated by multiple unit recordings. Soc Neurosci Abstr 16:894.

Llinás R (1986) Neuronal oscillators in mammalian brain. In: Comparative neurobiology: modes of communication in the nervous system (Cohen MJ, Strumwasser F, eds), pp 279-290. New York: Wiley.

Llinás R (1991) The noncontinuous nature of movement execution. In: Motor control: concepts and issues (Humphrey DR, Freund H-J, eds), pp 223-243. New York: Wiley.

Llinás R, Sasaki K (1989) The functional organization of the olivocerebellar system as examined by multiple Purkinje cell recordings. Eur J Neurosci 1:587-602.

Llinás R, Yarom Y (1981a) Electrophysiology of mammalian inferior olivary neurons in vitro. Different types of voltage-dependent ionic conductances. J Physiol (Lond) 315:549-567.

Llinás R, Yarom Y (1981b) Properties and distribution of ionic conductances generating electroresponsiveness of mammalian inferior olivary neurons in vitro. J Physiol (Lond) 315:569-584.

Llinás R, Yarom Y (1986) Oscillatory properties of guinea-pig inferior olivary neurones and their pharmacological modulation: an in vitro study. J Physiol (Lond) 376:163-182.

Llinás R, Baker R, Sotello C (1974) Electrotonic coupling between neurons in cat inferior olive. J Neurophysiol 37:560-571.

Lopez-Barneo J, Darlot C, Berthoz A, Baker R (1982) Neuronal activity in prepositus nucleus correlated with eye movement in the alert cat. J Neurophysiol 47:329-352.

Lou J-S, Bloedel JR (1986) The responses of simultaneously recorded Purkinje cells to the perturbations of the step cycle in the walking ferret: a study using a new analytical method-the real-time postsynaptic response (RTPR). Brain Res 365:340-344.
I ou J-S, Bloedel JR (1992) Responses of sagittally aligned Purkinje cells during perturbed locomotion: synchronous activation of climbing fiber inputs. J Neurophysiol 68:570-580.

McFarland JL, Fuchs AF (1992) Discharge patterns in nucleus prepositus hypoglossi and adjacent medial vestibular nucleus during horizontal eye movement in behaving macaques. J Neurophysiol 68: 319-332.

Nagao S (1983) Effects of vestibulocerebellar lesions upon dynamic characteristics and adaptation of vestibuloocular and optokinetic responses in pigmented rabbits. Exp Brain Res 53:36-46.

Partsalis AM, Zhang Y, Highstein SM (1993) The y group in vertical visual-vestibular interactions and VOR adaptation in the squirrel monkey. Soc Neurosci Abstr 19:138.

Sasaki K, Bower JM, Llinás R (1989) Multiple Purkinje cell recording in rodent cerebellar cortex. Eur J Neurosci 1:572-586.

Shojaku H, Barmack NH, Mizukoshi K (1991) Influence of vestibular and visual climbing fiber signals on Purkinje cell discharge in the cerebellar nodulus of the rabbit. Acta Otolaryngol (Stockh) [Suppl] $481: 242-246$.

Simpson JI, Graf W, Leonard CS (1981) The coordinate system of visual climbing fibers to the flocculus. In: Progress in oculomotor research (Fuchs A, Becker W, eds), pp 475-484. Amsterdam: Elsevier.

Sotello C, Llinás R, Baker R (1974) Structural study of inferior olivary nucleus of the cat: morphological correlates of electrotonic coupling. J Neurophysiol 37:541-559.

Sugihara I, Lang EJ, Llinás R (1993) Uniform olivocerebellar conduction time underlies Purkinje cell complex spike synchrony in the rat cerebellum. J Physiol (Lond) 470:243-271.

Takeda T, Maekawa K (1989a) Olivary branching projections to the flocculus, nodulus and uvula in the rabbit. I. An electrophysiological study. Exp Brain Res 74:47-62.

Takeda T, Maekawa K (1989b) Olivary branching projections to the flocculus, nodulus and uvula in the rabbit. II. Retrograde double labelling study with fluorescent dyes. Exp Brain Res 76:323-332.

Tan J, Gerrits NM, Nanhoe RS, Simpson JI, Voogd J (in press) Zonal organization of the climbing fiber projection to the flocculus and the nodulus of the rabbit. A combined axonal tracing and acetylcholinesterase histochemical study. J Comp Neurol, in press.

Thach WT (1967) Somatosensory receptive fields of single units in the cat cerebellar cortex. J Neurophysiol 30:675-696.

Waespe W, Henn V (1987) Gaze stabilization in the primate: the interaction of the vestibulo-ocular reflex, optokinetic nystagmus and smooth pursuit. Rev Physiol Biochem Pharmacol 106:38-125.

Waespe W, Cohen B, Raphan T (1983) Role of the flocculus and paraflocculus in optokinetic nystagmus and visual-vestibular interactions: effects of lesions. Exp Brain Res 50:9-33.

Waespe W, Cohen B, Raphan T (1985) Dynamic modification of the vestibulo-ocular reflex by the nodulus and the uvula. Science 228 : 199-202.

Welch JP, Lang EJ, Llinás R (1993) The microstructure of coherence in the olivocerebellar system during rhythmic movement in normal and deafferented rats. Soc Neurosci Abstr 19:1278.

Wylie DR, De Zeeuw CI, DiGiorgi PL, Simpson JI (in press) Projections of individual Purkinje cells of identified zones in the ventral nodulus to the vestibular and cerebellar nuclei in the rabbit. J Comp Neurol, in press. 